\title{
Needs To Be in Port Accident Emergency System Construction and Assessment Technology Research
}

\author{
Shijie Zhang ${ }^{1}$, Shuifen Zhan ${ }^{1,2}$, Yukun Wang ${ }^{1,2 *}$ \\ ${ }^{1}$ Tianjin Research Institute for Water Transportation Engineering, M. O. T., Tianjin 300456, China \\ ${ }^{2}$ Tianjin Dongfang Tairui Technology CO. LTD, Tianjin 300456, China
}

\begin{abstract}
In this paper, the urgency and necessity of the research on the construction and evaluation technology of China's port accident emergency response system are fully expounded and demonstrated from the level of the policies and documents of the administrative departments, the research level of experts and scholars, and the actual situation of the port industry emergency response work. Based on sorting out the problems existing in the construction and evaluation of China's port accident emergency response system, the research ideas and main contents of the research on the construction and evaluation technology of port accident emergency response system are put forward.
\end{abstract}

\section{Introduction}

In recent years, with the continuous expansion of industrial production demand, the annual throughput through China's ports is increasing year by year, the number and scale of operating goods are also expanding. Among them, thousands of kinds of dangerous goods have been transported by waterway in China, accounting for more than $20 \%$ of the total waterway transportation volume. Dangerous goods have a variety of risks such as combustion, toxicity, pollution, and reactivity, and there are many quantities and varieties of dangerous goods. Once an accident occurs, it will cause serious damage to human health, the natural environment, and social and economic development. If the emergency response is not timely or wrong, it is easy to cause a domino effect and expand the impact of the accident.

Although the impact range of accidents caused by other port operations other than dangerous goods is not as large as that caused by dangerous goods, due to the characteristics of the port itself, it is also easy to cause greater economic losses and more than large production safety accidents. Therefore, ordinary cargo operations should not be underestimated.

Port enterprises not only need to prevent the happening of production safety accidents, and should be able to quickly after the accident effectively will harm the scope and degree of control to a minimum, this requires port enterprises to build effective emergency system, to strengthen the construction of the emergency ability, strengthen emergency equipment, improve the level of the emergency infield, and make the scientific assessment to ensure the effectiveness of the emergency system.

Through the research on the construction of port accident emergency system and the evaluation technology of emergency capacity, this paper provides the basis for the formulation of scientific and systematic guidelines for the construction of port accident emergency system and the evaluation of emergency capacity, to guide enterprises to establish and perfect the safety production emergency system and improve the level of emergency capacity of enterprises.

\section{Research purpose and meaning}

At present, positive progress has been made in the work of port safety in China, but the long-term accumulation of profound contradictions and safety risks have not been eradicated, and the foundation of safe production is still weak. In particular, the "8.12" dangerous goods warehouse of Ruihai Company in Tianjin Port, which caused serious casualties and property losses. Frequent major accidents show the following problems: the concept of safety in production is not in-depth, the construction of the emergency system is not perfect, the emergency capacity is not suitable for the rapid development of the economy and other problems.

Bloodshed lessons and the cost of a human life fully prove that the lives of people are at stake in workplace safety, and the responsibility of safety is more important than Mount Tai. To ensure safety is to promote development, and without safety, nothing can be discussed. Work safety bears on the safety of people's lives and property, on the reform and opening up, and on the overall situation of economic development and social stability.

In port construction accident emergency system and assessment technology research, the research results can help enterprises enhance the level of emergency management, equipped with reliable and efficient emergency rescue equipment, strengthen enterprise 
emergency ability, make up the emergency ability, perfect the port production safety emergency resource allocation, promote enterprise's emergency ability level, to ensure safety in production work. The research results can provide technical support for the government or relevant competent departments to strengthen safety emergency supervision and formulate relevant guidance documents, and can also provide a reference for the construction and evaluation of emergency response systems and capacity for other key fields and industries.

\section{Recent policy and document requirements}

The ability of enterprises to prevent and deal with unexpected accidents is one of the important factors to measure the level of emergency management of the region and enterprises, and it is also an important basis for mitigating and mitigating the loss caused by accidents. In recent years, the State Council and the Ministry of Transport have promulgated a series of policies and documents which set forth requirements for emergency management, emergency capacity building, and capacity assessment.

To comprehensively strengthen emergency management, the State Council issued the Opinions on Comprehensively Strengthening Emergency Management in 2006 [1], which proposed to "strengthen capacity building for responding to emergencies and improve the emergency management capacity at the grass-roots level". The 13th Five-Year Plan of the Ministry of Emergency Management proposes to improve the long-term mechanism of emergency assessment. We will promote regular and institutionalized emergency preparedness capacity assessments.

National Work Safety Emergency Rescue Command Center in 2017 work safety emergency management points also pointed out to strengthen work safety risk assessment and emergency assessment work. Formulate emergency assessment work norms, and define assessment work contents, processes, methods, and requirements.

As the competent department of the industry, the Ministry of Transport has also put forward some requirements for emergency resource allocation and emergency capacity assessment in various documents. The Opinions of the General Office of the Ministry of Transport on Strengthening the Safety Management of Dangerous Goods Tanks at Port (Jiaowaterban[2017] No.34) [2] requires that safety risk and emergency capability assessment be carried out in the areas where the operation of dangerous goods is concentrated, such as the port storage tank area. "Port of dangerous goods safety management regulation" (transportation ministry make no. 34, 2019)[3], prescribed in article "the local port administrative department shall be under the leadership of the local people's government of promoting the construction of professional emergency team and emergency resources reserve, regularly organize emergency training and emergency rescue drill, improving emergency ability". The Ministry of Transport Notification on the issuance of the Special Action Plan for the Safety Management of Dangerous Goods Port Operation (2016-2018) " (Jiaoshuifa [2016] No. 5)[4] also stipulates that accident risk analysis and emergency response capability assessment should be organized in areas where major hazard sources are concentrated.

\section{Research situation of scholars in recent years}

Compared with developed countries in emergency management, the study of emergency management in China started relatively late, and it was not until the end of the 1980s that China gradually researched the evaluation of urban emergency capacity.

In 2002, Professor Wang Shaoyu studied the contents of urban disaster emergency response capacity construction and divided the urban disaster emergency response capacity evaluation system into three system elements: disaster risk assessment, urban vulnerability assessment, and urban disaster emergency management capability assessment [5].

Deng Yunfeng and Zheng Shuangzhong et al. constructed the basic framework of urban emergency capability assessment system in the study of "Key Technologies for Urban Emergency Capacity Assessment Research and Emergency Assistance Decision Support System", which is similar to the 13 functions contained in Car in the United States and is divided into 18 categories, 76 attributes and 405 features [6].

Tie Yongbo studied the evaluation index system of urban disaster emergency response capacity based on the characteristics of urban disasters and divided the evaluation index system of urban disaster emergency response capacity into 6 first-level indexes and 23 second-level indexes, including urban disaster monitoring and early warning ability, urban disaster prevention ability, rapid response ability of government departments, urban residents' emergency response-ability, emergency rescue ability and resource guarantee ability [7].

Based on the theory of process management, Yang Qing, Tian Yilin et al., divided the comprehensive capability evaluation system of urban disaster emergency management into three sub-systems, including predisaster warning capability evaluation, in-disaster emergency response capability evaluation, and postdisaster recovery capability evaluation, and 12 subsystems [8].

These research results have played a positive role in promoting the research of China's emergency response capacity assessment, but these studies are more focused on the assessment of urban disaster emergency response capacity, and less involved in enterprises and other grass-roots emergency response capacity research. Emergency response capacity is a concept relative to the subject. The level of emergency response subjects is different, and the corresponding requirements are 
different. Therefore, the emergency response capacity assessment system and model applicable to cities are not necessarily applicable to the grass-roots emergency response subjects such as enterprises [9].

Therefore, it is necessary to combine the present situation of port safety management, and comprehensively consider the characteristics of port safety production accidents, and establish the index system of port emergency capacity evaluation, to scientifically reflect the emergency capacity level of port enterprises.

\section{At the present stage existence deficiency}

For sudden accidents, China's emergency management in the "heavy rescue and light prevention" phenomenon, the lack of various factors caused by the crisis from the potential to the outbreak of a series of rules of exploration, resulting in great harm, weakened the construction of defense capacity.

At present, the problems existing in the construction of the emergency system and emergency capacity of port enterprises are mainly shown in the following aspects:

1) The construction and standardization of "One Case and Three Systems" are not sufficiently deepened

In the construction of emergency plans, the existing various emergency plans are more abstract and less operable, and some even become the "decoration" for the inspection. The drill and evaluation of the plan are a mere formality, and the revision of the plan is lagging. In the aspect of legal construction, the supporting systems and measures that need to be formulated according to national emergency laws, regulations, standards, and norms are still not perfect and need to be further refined. In terms of system construction, the relationship between port enterprises and departments responsible for production safety supervision and administration in emergency work needs to be further straightened out, and the relevant responsibilities in emergency work need to be further clarified. In the aspect of mechanism construction, the connection between the local enterprises and the upper and the lower is still relatively weak.

2) Emergency response and rescue capabilities need to be strengthened

The number of full-time (part-time) emergency rescue teams of port enterprises is insufficient, and the rescue capability training and emergency drill are not enough, the professional rescue equipment is insufficient, the coordination mechanism between the port enterprises and the local professional emergency rescue teams is not perfect, and the responsibilities and scope of responsibility of relevant parties are not clear. There is not enough match between the types of emergency supplies and the actual operation requirements. Some port enterprises rely on each other, but the synergistic mechanism is not clear, and it is difficult to fully guarantee emergency public supplies after the occurrence of emergency accidents. The joint emergency response measures are not specific and cannot be effective. Emergency warning, information reporting, and emergency response processes need to be further standardized. After the occurrence of sudden accidents, the construction of an emergency response mechanism should be further strengthened, in which the causes, development trends, and impact areas of accidents are rapidly evaluated and decisions are made quickly.

Emergency capability is the ability to use emergency resources to effectively control and manage the causes and consequences of production safety accidents and minimize accidents, casualties, and property losses in the whole cycle of accident development from prepreparation, in-process response to post-recovery based on the principle of accident prevention. Emergency capacity is the comprehensive embodiment of enterprise emergency management and plays a key role in the rescue activities of production accidents. Therefore, every enterprise needs to build an emergency system and have the capacity of safe production emergency matching with the emergency needs.

At present, especially in the port industry in China there is no perfect emergency system and ability construction guidance document or standard, enterprise for its emergency ability can only through the plan, fire fighting equipment configuration, individual protection on single including emergency preparedness work, there is no definite criteria to determine whether an enterprise that can meet the needs of its production and operation situation emergency ability.

\section{The main research ideas and content}

Proposes the research idea and the content of this study, combined with the existing production safety laws and regulations, standards, specification requirements, according to the characteristics of port accident type and the research to determine the port enterprises should have accident emergency ability, on this basis, promotes the port enterprise accident emergency system and emergency capability assessment technology research, develop port emergency response system and emergency capability assessment method.

(1) Organize and analyze the requirements of the existing laws, regulations, standards, and norms of work safety, to provide basic support for the construction of the emergency system and the evaluation index of emergency capacity.

(2) By combing and analyzing typical cases of major and major accidents, detailed accident causation analysis results were presented, and emergency experience and lessons were summarized to lay a foundation for emergency system construction and emergency capacity evaluation indicators.

(3) from the organization system, the legal basis, operation mechanism, and the safeguard system and so on four aspects to study and put forward pertinence and maneuverability of the emergency system construction and emergency capability assessment elements, and to guide the construction of port enterprises to grasp the emergency ability core points and practical significance for the key link, to the departments responsible for the 
port of the supervision and administration of production safety emergency system construction, supervision and inspection following the port enterprise and the emergency capability assessment work has a certain guiding role.

The Study technical route flow is shown in the following figure (Fig. 1).

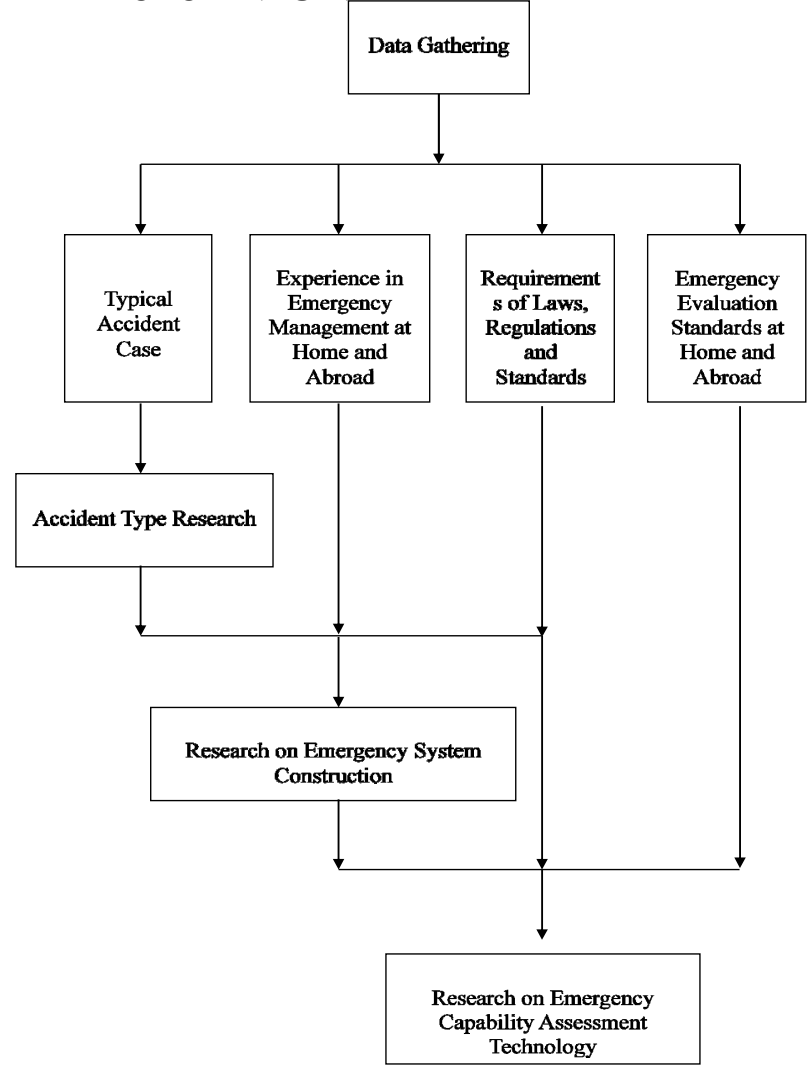

Fig. 1. Study technical route flow chart

\section{Conclusion}

This paper, starting from the actual situation of emergency work in the port industry, describes the policy and document requirements of the state and the Ministry of Transport for the construction and evaluation of the emergency system in recent years, summarizes the research status of Chinese experts and scholars in the construction and evaluation of the emergency system in recent years, and summarizes the existing problems in the construction and evaluation of port accident emergency system in China. Because of the lack of systematic and complete guidance documents and standards for the construction and evaluation of emergency response capacity in China's port industry, the necessity and urgency of developing the construction and evaluation technology of port accident emergency response system for the safety of China's waterway transportation and port industry at the present stage are fully introduced. At the same time, this paper preliminarily discusses the research ideas and main contents of the research on the construction and evaluation technology of the port accident emergency system, which provides the basis for the development of the scientific and systematic construction of the port accident emergency system and the evaluation guide of the emergency capacity, to guide enterprises to establish and perfect the safety production emergency system and improve the level of the emergency capacity of enterprises.

\section{Acknowledgement}

This research is supported by the Fundamental Research Funds for the Central Public Welfare Research Institutes (Grant Nos. TKS190108).

\section{References}

1. The People's Government Network of the People's Republic of China. Opinions on Comprehensively Strengthening Emergency Management[EB/OL]. [2006-06-15]. http://www.mot.gov.cn/.

2. The People's Government Network of the People's Republic of China. Opinions on Strengthening the Safety Management of Dangerous Goods Storage Tanks in Ports[EB/OL]. [2017-03-08]. http://www.mot.gov.cn/.

3. The People's Government Network of the People's Republic of China. Provisions for the Safety Control of Dangerous Goods in Port [EB/OL]. [2019-11-28]. http://www.mot.gov.cn/.

4. The People's Government Network of the People's Republic of China. Notice of the Ministry of Transport on Issuing the "Special Action Plan for the Safety Governance of Dangerous Goods Port Operations (2016-2018)" [EB/OL]. [2016-04-20]. http://www.mot.gov.cn/.

5. X.Y. Wu, J.H. Gu. Research progress on urban disaster emergency response capability evaluation at home and abroad $[\mathrm{J}]$. Journal of Natural Disasters, 2007, 16(6):109-114 pp.

6. S.Y. Wang. The construction of urban disaster emergency management capacity and disaster reduction[J]. City and Disaster Reduction, 2003, (3): 4-6 pp.

7. Y.F. Deng, S.Z. Zheng, G.Z. Liu. Study on Urban Emergency Capability Assessment System [J]. Journal of Safety Science and Technology, 2005, 1(6):33-36.

8. Y.B. Tie, C. Tang. Construction of Urban Disaster Emergency Response Capability Evaluation Index System [J]. Urban Problems. Urban Problems, 2005, (6) :76-79 pp.

9. Q. Yang, Y.L. Tian, Y.H. Song. Research on the comprehensive ability evaluation system of urban disaster emergency management based on process management $[\mathrm{J}]$. China Administration Management, 2007, (3) :103-106 pp. 